\title{
Analysis on the Problems and Countermeasures of China's Enterprises' Import and Export Trade in the New Period
}

\author{
Bo Liu \\ English School, China West Normal University, Nanchong City, Sichuan Province, 637009, China
}

Keywords: New era; Enterprise; Import and export trade; Countermeasures.

\begin{abstract}
In the new period, the import and export trade volume of Chinese enterprises is rising, which has a great influence on the national economic development. In recent years, although the level of Chinese enterprises import and export trade has improved, there are still many problems. In view of the current situation of import and export trade of Chinese enterprises, this paper pointed out the problems existing in the import and export trade of small and medium-sized enterprises in China, and put forward effective solutions to realize the good development of import and export enterprises.
\end{abstract}

\section{Introduction}

With the rapid development of economic globalization, more and more enterprises are gradually go out of the country to enter the international market and participate in international competition, which becomes an important force to promote the development of our national economy and foreign trade ${ }^{[1]}$. Although the total volume of import and export of Chinese enterprises is increasing rapidly, we should clearly realize that the international competitiveness of our enterprises is insufficient and is still in a disadvantageous position in foreign trade. Therefore, it is of great significance to analyze the problems of foreign trade development of import and export enterprises and put forward corresponding countermeasures to guide the sustained and healthy development of Chinese enterprises' foreign trade.

\section{Problems Existing in the Import and Export Trade of Chinese Enterprises in the New Period}

\subsection{Weak brand awareness}

In the new period, due to the production scale, capital, technology, talent and other constraints, the quality of products is often not guaranteed. Thus, it is difficult to form their own brands. The disadvantages including no technology and other core patents have weakened the competitiveness of our enterprises' products in the international market. At present, most of the products of many enterprises in China are concentrated in labor-intensive industries. Many enterprises without economic strength simply rely on imitating other products, or open up the road of operation by means of label production. In the short run, this effect is obvious and will bring large profits to enterprises. However, in the long run, it is not conducive to the sustainable development of enterprises and is easy to perish in homogeneous competition. Brand is not only the label of a product, but also the vitality of an enterprise. Without the brand, the sustainable development of the enterprise will be greatly affected.

\subsection{Weak technological innovation capacity}

The core competitiveness of our products originates from scientific and technological innovation. Compared with the enterprises in developed countries, many enterprises in China are backward in equipment, technology, and low in scientific and technological content and added value, which makes China enterprise lacks the ability of independent innovation generally. Judging from the current development trend, the product imitation is serious, and the low price strategy is mainly 
adopted in the international trade, which leads to the increasing number of anti-dumping investigations against China. Trade and technical barriers seriously hamper the internationalization of enterprises in China and become the biggest obstacle to international trade in import and export enterprises. In the new period, China's technological innovation resources are mainly concentrated in large enterprise groups. Many enterprises in China has very limited innovation resources and serious shortage of innovation investment.

\subsection{Unreasonable commodity structure}

In the new period, the product structure of China's import and export enterprises is unreasonable in two aspects: First, the product competitive advantage is insufficient. China currently exports low value-added labor-intensive products and primary manufactured goods, while imports of capital, technology-intensive products and high-value-added manufactured goods are less exported. Second, the profit margin is greatly reduced. Most of China's exports are labor-intensive products with relatively low added value and relatively small technical content. Because of the low price and the very small profits, enterprises can't invest the money into technology development and innovation. Because of the vicious circle, the innovation ability of enterprises cannot be improved, and the competitive advantage of export products in the international market is weakened, so the competitiveness is not improved.

\subsection{Lack of international talent}

China's import and export enterprises are mostly family-centered, which is based on the basic conditions of rural management. Therefore, no matter the owner, the operator or the ordinary operator, there is a lack of scientific and technological knowledge, and management methods and management methods lag behind. Managers often lack some necessary management knowledge, and they only rely on their own management, which is easy to appear problems. Foreign trade personnel are also selected from the management of domestic trade, and foreign language and foreign trade knowledge are the biggest weaknesses of China's enterprises import and export trade $^{[2]}$.

\subsection{Non-standard operation and management}

In the new period, the problems of non-standard management of import and export enterprises in China are reflected in three aspects. Firstly, the internal management system is not perfect, which directly leads to the low level of enterprise management. The lack of standard organization mode leads to the individual playing the main role in the decision-making of the import and export trade of the enterprise, and once the decision is wrong, it will directly lead to the destruction of the enterprise. Finally, due to the fierce competition in the market and the limitations of the existing conditions, many enterprises excessively pursue short-term profits, still staying in the traditional concept of "good and cheap". They only use low prices as a means of competition, and spend less on research and development, marketing and opening up market.

\subsection{Information channels are not clear}

At present, the import and export enterprises in China cannot get the needed information in time because of their own conditions. Moreover, it is easily influenced by the subjective factors of the decision makers, which leads to the low efficiency of information collection in the international market. Information processing and feedback ability is weak, lacking of comprehensive and dynamic understanding of the international market. In addition, our import and export American trade enterprises in the process of carrying out foreign trade and obtaining information is relatively backward, lacking of understanding of the international environment, so it is easy to bring large losses to enterprises. 


\section{The Strategy of Dealing with the Import and Export Trade of Chinese Enterprises in the New Period}

\subsection{Building an international brand}

Brand is a strategic core asset of an enterprise. Brand shows the fruits of development, and quality is also pregnant with the vitality of the challenge. In the process of international trade cooperation and exchange, enterprises should thoroughly change the product concept, and actively create international brand. First, China's import and export enterprises should accurately investigate the market, analyze the target market according to the needs of the target market, and carry out a reasonable positioning, concentrate their own resources to create a proprietary brand, so that to constantly carry out brand innovation and improve their core competitiveness. Second, it is necessary to guide import and export enterprises to actively carry out technological innovation, and to set up special centers in qualified enterprises, so that to equip high-quality scientific research personnel and to transform advanced science and technology into effective productive forces in a timely manner ${ }^{[3]}$. Third, it is necessary to guide import and export enterprises to introduce advanced foreign production technologies and to carry out technological transformation and industrial upgrading of existing technological facilities, so that to promote the continuous upgrading of products and to reduce the cost of technological innovation and to improve the international competitiveness of enterprises.

\subsection{Support for financing services}

In order to improve the trade level of our import and export enterprises in the new period, we must establish a financing service system that meets the actual needs and broaden the financing channels of our enterprises. The first is to allow the corporate enterprises to carry out equity financing and guide the folk financing to a standardized, transparent and scientific way. At the same time, we should actively and steadily promote the equity reform and asset restructuring of local financial institutions and related financial organizations. Second, we should increase the strength of financial support, set up our enterprise foundation and arrange special funds to provide a certain proportion of interest discount support to import and export enterprises. Financial institutions that carry out innovative financing services for import and export enterprises are given appropriate financial incentives to mobilize the enthusiasm of financial services institutions and to further reduce the financing costs of enterprises.

\subsection{Implementation of structural optimization and upgrading}

In order to improve the level of import and export trade in the new period, we must optimize our own structure and promote the upgrading and transformation of the structure. Industrial cluster can help to establish more domestic regional brands, enhance the competitiveness of products in the region and promote the rapid development of regional economy. Specific measures are: First, proceeding from the actual situation of economic development in the enterprise region, we should carefully plan, rationally allocate the resources within the region, and broaden the industrial chain. We should actively promote the relevant industries to gather purposefully and construct a functional industrial layout. Second, it is necessary to increase government investment in infrastructure, provide guidance for enterprises in industry, build public service platform, improve its cluster function, release the vitality of industrial cluster and promote industrial upgrading. Third, the enterprises of China should take the large enterprises as the center, carry out the supporting cooperation and transform from extensive management to intensive operation to meet the development needs of our import and export enterprises in the new period ${ }^{[4]}$.

\subsection{Speed up the training of foreign trade talents}

Talent for import and export enterprises is extremely important. From familiarity with the international market environment, research on the needs of consumers, development of suitable products, pricing, distribution and promotion, research and development and channels to terminals, 
this chain of personnel configuration is indispensable. To speed up the cultivation of foreign trade talents, we should: first, we should change the traditional training mode and train compound professionals. On the one hand, we should strengthen the ideological and cultural quality of the talents in import and export trade and help them to improve their knowledge structure so that to enhance their professionalism. On the one hand, we can carry out comprehensive professional knowledge training and strengthen the training of practical skills through the foreign trade talents. Second, focusing on the needs of local industries, foreign trade talents should be trained on entry, skills, orders and on-demand training to meet the needs of enterprises and workers.

\subsection{Perfect enterprise management in China}

In order to further standardize the operation and management of Chinese enterprises in the new period, it is necessary to guide enterprises to operate in good faith, operate according to law and standardize management. Only in this way, can continuously improve the competitiveness of the market and can continue to enhance the credibility of enterprises. We should improve the management of import and export enterprises. First, we should set up a modern enterprise management system, guide our enterprises to change the family management mode, carry out the modern management system, call on the enterprises to improve their related system construction and establish a comprehensive, transparent and real financial system. The second is to increase the reform of enterprise property right system. In the form of strategic alliances, mergers, acquisitions, contracting, and equity participation, we should take the road of joint development, so that to urge them to change the management system, strengthen management at the root and improve the quality of export commodities. Moreover, it can improve the ability to open up the international market and enhance the strength of the international multinational companies.

\subsection{Channels of widening information}

To get the international market information quickly, as for China's import and export enterprises, they are inseparable from information services. First, the relevant government departments should improve the information asymmetry of Chinese enterprises, set up a set of information consulting service system suitable for Chinese enterprises, and achieve unimpeded information channels. Second, we should constantly improve the information network, build an information service platform, and speed up the construction process of the websites of our import and export enterprises. Relevant government departments should constantly improve and update the relevant policies, laws, technologies and services on the website, so that to improve the website information guidance and transmission function and provide precise policy information for enterprises. Information such as industry dynamics makes the website a good platform for import and export enterprises to operate services and seek help. Third, we should accelerate the construction of import and export enterprises' own websites, improve the related functions of the website homepage, and highlight the product characteristics of the enterprises. We should increase the function of linking websites, promote the communication and sharing of information between enterprises and government departments, so that to set up a good corporate image.

\section{Conclusions}

To sum up, there are still some problems in the development of foreign trade of China's import and export enterprises. Under the circumstances of the accelerated development of economic globalization and the increasingly complex international economic environment, the import and export trade of enterprises should be based on the long-term, enhance the ability of innovation, carry out brand strategy, upgrade the product structure and change the trade mode so as to achieve long-term, healthy and stable development of foreign trade.

\section{References}

[1] Yang Sulin. Problems Existing in Import and Export Clearance of Foreign Trade Enterprises in 
the New Period and Their Solutions [J]. The Practice of Foreign Trade and Economic Cooperation, 2016(03): 67-69.

[2] Kong Xue. Research on Foreign Trade Development of Private Enterprises in China under the Background of Economic Globalization [J]. Mall Modernization, 2016(14): 13-14.

[3] Chen Jiaqian, Zhu Hui. A Study on the Problems and Countermeasures of China's Small and Medium-sized Enterprises' Import and Export Trade [J]. Business Guide, 2011(16): 13.

[4] Wu Zhenqian, Yang Zhenning, Jia Huaiqin. Current Situation and Expectation of Import and Export of China's Private Enterprises in the Predicament of Foreign Trade [J]. Journal of the Capital University of Economics and Technology, 2013, 15(04): 66-71. 